\title{
Reflexões Sobre Noções de Integralidade e Necessidades Sociais em Cuidados de Saúde
}

\author{
Luiz Alberto Ruiz da Silva ${ }^{1}$, Bruna Tadeusa Genaro Martins de Oliveira ${ }^{2}$, \\ Gleizze llana Gomes ${ }^{3}$, Ana Carolina Sacco ${ }^{4}$
}

\begin{abstract}
RESUMO
Este artigo tem por objetivo a análise e a reflexão sobre as noções de integralidade e o sentido que tais elementos causam nas necessidades sociais em saúde. Qual a necessidade do estudo de um conceito para a formação de uma política pública na área de saúde? Qual a importância em se discutir, a partir de uma premissa histórica, a formação das noções de integralidade e como estas noções se relacionam com as necessidades sociais em saúde? Foi partindo dessas questões que o presente artigo foi construído, procurando observar a formação das noções de integralidade bem como dos seus significados, tendo como base para tal uma abordagem histórica. Nesta análise pode ser observada a necessidade de se fazer com que as ideias em relação às noções de integralidade sejam inseridas na formação dos profissionais de saúde, tendo a percepção de que ainda não existe uma ação prática em campo neste processo de formação e no serviço oferecido à população. Dessa forma, é necessário uma reformulação no modo como é conduzida a formação profissional, fazendo com que sejam destacadas as noções de integralidade aplicadas às necessidades sociais em saúde, dentro do contexto de atuação. Esse contexto constitui-se em uma proposta de ação estratégica para transformar a organização dos processos formativos e dos serviços oferecidos à população, implicando compreensão da saúde a partir de uma visão ampliada e totalizante.
\end{abstract}

Palavras-chave: Integralidade em saúde. Necessidades sociais em saúde. História dos conceitos. Formação profissional.

\section{REFLECTIONS ON NOTIONS OF INTEGRALITY AND SOCIAL NEEDS IN HEALTH CARE}

\section{ABSTRACT}

This article aims to analyze the integrality notions and the sense that such elements cause in health social needs. What is the need to study a concept for the design of a public health policy? What is the importance of discussing, from a historical premise, the construction of the notions of integrality and how do these notions relate to health social needs? The present article was constructed from these questions, by analyzing the notions of integrality, as well as their meanings, based upon a historical approach. In this analysis it was possible to observe the need to include the ideas regarding notions of integrality in the training of health professionals, having the perception that there is still no practical action in the training process as well as in the service offered to the population. In this way it is necessary to reformulate the way in which professional training is conducted, so that the notions of integrality applied to health social needs are highlighted, within the context of action. This context is constituted by a proposal of strategic action to transform the organization of the training processes and the services offered to the population, implying an understanding of health from a wider and holistic vision.

Keywords: Integrality in health. Social needs in health. History of concepts. Professional training.

RECEBIDO EM: 11/5/2017

MODIFICAÇÕES REQUERIDAS EM: 24/9/2019

ACEITO EM: 8/11/2019

\footnotetext{
Graduado em Educação Física pela Universidade Federal da Grande Dourados. Especialista em Ciências do Envelhecimento Humano e Mestre em Ensino em Saúde pela Universidade Estadual de Mato Grosso do Sul. http://orcid.org/0000-0002-3257-1196. luizalbertoruiz91@gmail.com

2 Graduada em Psicologia pela Universidade Estadual Paulista. Especialista em Ciências do Envelhecimento Humano e Mestra em Ensino em Saúde pela Universidade Estadual de Mato Grosso do Sul. Doutoranda em Bioética, Ética Aplicada e Saúde Coletiva, pela Universidade Federal Fluminense. bruna_genaro@yahoo.com.br

${ }^{3}$ Graduada em Enfermagem pelo Centro Universitário da Grande Dourados. Mestra em Ensino em Saúde pela Universidade Estadual de Mato Grosso do Sul. enfgleizze@hotmail.com

${ }^{4}$ Graduada em Enfermagem pela Universidade Estadual de Mato Grosso do Sul. Mestra em Ensino em Saúde pela Universidade Estadual de Mato Grosso do Sul. carol.enf86@hotmail.com
} 


\section{INTRODUÇÃO}

Com a instituição da Constituição Federal de 1988, a saúde foi declarada direito de todos e dever do Estado brasileiro. Assim, definiu-se o que ficou conhecido historicamente como Sistema Único de Saúde (SUS), cujas ações e serviços compõem uma rede hierarquizada e descentralizada que presta atendimento integral e conta com a participação da comunidade no desenvolvimento de suas atividades (BRASIL, 1988).

A ideia de integralidade chama a atenção, neste contexto, por marcar uma premissa importante no que se refere ao serviço de saúde no Brasil. Assim, qual a necessidade do estudo de um conceito para a formação de uma política pública na área de saúde? Qual a importância de discutir, a partir de uma premissa histórica, a formação das noções de integralidade e como estas noções se relacionam com as necessidades sociais em saúde? Foi partindo destas questões que o presente artigo foi trabalhado, procurando observar a formação das noções de integralidade bem como dos seus significados, tendo como base uma abordagem histórica.

Mendonça (1983) aponta para a necessidade de um mínimo de conhecimento prévio sobre o elemento-chave ao qual se quer trabalhar, como as noções de integralidade. Para tanto, a autora preconiza que o entendimento da origem histórica do conceito é fundamental para a sua compreensão, pois permite a quem se debruça sobre o objeto o entendimento dos motivos pelos quais tal conceito tornou-se importante. Daí nossa problematização: Por que as noções de integralidade são importantes para a compreensão das necessidades sociais em saúde?

Cremos ser possível responder a esta pergunta se observarmos a construção das noções de integralidade que se operam em diversos níveis, criando, assim, um elemento que permite a comunicação para “(...) representar uma determinada realidade" (MENDONÇA, 1983, p. 15), permitindo a apreensão do seu significado. É importante compreender metodologicamente o significado da ideia de construção de certo conceito para entender a sua aplicabilidade.

\section{A CONSTRUÇÃO DAS NOÇÕES DE INTE- GRALIDADE - RELAÇÕES COM O PROCES- SO HISTÓRICO BRASILEIRO}

Quando pensamos na ideia de noções de integralidade, devemos pensá-la dentro de uma construção lógica, que foi estabelecida a partir de um quadro referencial, e que, a partir dele, adquiriu significado dentro de um esquema de pensamento a ponto de se tornar uma das diretrizes básicas do Sistema Único de Saúde (SUS) (MATTOS, 2009), mesmo que a palavra não esteja explícita no documento das diretrizes básicas do SUS, de forma direta, conforme aponta Mattos (2009). ${ }^{5}$

Assim, a ideia de noções de integralidade passou a representar um fenômeno, ou aspectos dele, que se desenvolvia no mundo real e que passou a ter efetiva existência a partir do momento em que foi nomeado, permitindo a representação de uma necessidade. É assim que se constitui o chamado "processo de conceituação" (MENDONÇA, 1983, p. 17), a partir do qual é possível simplificar uma determinada forma de pensamento pautando-a em uma ou em poucas palavras.

Por que a ideia de noções de integralidade, expressa nas diretrizes básicas do SUS, adquiriu esta importância e a partir daí passou a ter o prisma que lhe é concedido? Historicamente é possível perceber a construção deste processo quando observamos que, no Brasil, até 1988 e, portanto, até a chamada Constituição Cidadã, havia uma séria dificuldade de que houvesse acesso garantido a toda população às chamadas necessidades básicas, entre elas a saúde.

Isso deve-se ao fato de que o sistema de saúde anterior à instalação do SUS era gerido pelo Instituto Nacional de Previdência Social, no qual o acesso ao atendimento médico era privado. Àqueles que não tinham condições de fazê-lo (no caso a maioria da população brasileira) só restava uma opção: procurar um dos hospitais que atendiam de forma gratuita, as chamadas "Santa Casa de Misericórdia" (PAIM et al., 2011).

Essa é uma marca longitudinal que acompanha a formação do país. Pautado em uma estrutura econômica que envolvia o tripé monocultura, latifúndio e escravidão (plantation), desde o Brasil colonial percebemos a concentração de renda em uma faixa muito específica da população (PRADO JR., 2011). A disponibilidade financeira devida a esta concentração de renda fez com que se efetivasse no país uma linha muito definida entre os detentores dos meios de produção e da renda e aqueles que tinham como opção a venda da sua força de trabalho.

\footnotetext{
O texto da Constituição de 1988 fala sobre “(...) atendimento integral, com prioridade para as atividades preventivas, sem prejuízo dos serviços assistenciais" (artigo 198).
} 
Neste sentido, o Estado brasileiro viu nascer a ideia de pobreza e dentro dela os seus desdobramentos, que significam e atingem pessoas sem uma habitação apropriada, sem acesso a uma alimentação adequada, serviços de saúde, saneamento básico, educação, entre outras necessidades básicas. Resumidamente, foi este processo, relacionado à ideia de pobreza, que deu origem ao esforço proposto pela Constituição de 1988 em reconhecer e fazer valer, no caso da saúde,

(...) um sistema único (o SUS), integrado pelas ações e serviços públicos de saúde, mas do qual também podem participar, em caráter complementar, instituições privadas. O que caracteriza esse Sistema Único de Saúde (que de modo algum é o único sistema de saúde no Brasil) é o seu financiamento público. Esse sistema único de saúde estaria organizado em torno de três diretrizes: a descentralização, com direção única em cada esfera de governo; $o$ atendimento integral; e a participação da comunidade (MATTOS, 2009, p. 43 , grifo nosso).

A posição adotada pelo Brasil, revelando a influência do Estado nas políticas nacionais de saúde apresenta um grande contraste em relação ao que o Banco Mundial preconizava para os países em desenvolvimento, naquele momento histórico (transição dos anos 80 para os 90) (MATTOS, 2009). De acordo com o Banco Mundial , a política proposta pelo Brasil estabelecia-se em uma base que não funcionava, principalmente pautada na ideia da gratuidade para todos os usuários do serviço de saúde.

Diante do reflexo do processo histórico, podemos compreender a concepção adotada no Brasil em relação a tal serviço. Esta concepção é pautada em um posicionamento político que veio como resposta ao período da ditadura militar e que contou com pessoas engajadas à causa em prol de uma sociedade mais justa, contrapondo uma nova forma de pensar a sociedade brasileira, em oposição ao modelo tradicional imposto pelo plantation. Moacyr Scliar (2007) corrobora esta afirmação ao propor que:

O conceito de cuidados primários de saúde tem conotações. É uma proposta racionalizadora, mas é também uma proposta política; em vez da tecnologia sofisticada oferecida por grandes corporações, propõe tecnologia simplificada, "de fundo de quintal". No lugar de grandes hospitais, ambulatórios; de especialistas, generalistas; de um grande arsenal terapêutico, uma lista básica de medicamentos - enfim, em vez da "mística do consumo", uma ideologia da utilidade social. Ou seja, uma série de juízos de valor, que os pragmáticos da área rejeitam. A pergunta é: como criar uma política de saúde pública sem critérios sociais, sem juízos de valor? (p. 39).

Assim, a ideia de noções de integralidade vai muito mais além do que a diretriz proposta pelo SUS. Ela possui uma polissemia (MATTOS, 2009) que se encontra com a ideia de que o conceito é uma palavra capaz de expressar uma abstração que surge pela generalização das vontades pessoais dentro de um determinado momento histórico expresso nas terminologias "bandeira de luta", "causa", "sociedade engajada", "engajamento", e que reflete a necessidade social em um contexto, qual seja, o da Reforma Sanitária ${ }^{6}$ e de seu posicionamento de resistência (junto com outras esferas da sociedade) em relação à ditadura militar nos anos 70 .

Posteriormente ao ano de 1984, quando o primeiro presidente civil foi eleito depois de 20 anos, é possível perceber uma série de medidas tomadas no sentido de promover a democratização (e, portanto, garantir o acesso) da saúde. Entre estas alternativas, a ideia de integralidade aparece, mesmo que indiretamente, como anui Cordeiro (2004), em razão das Ações Integradas de Saúde (AIS).

$\mathrm{O}$ quadro apresentado até aqui permite perceber a construção de um processo que levou a pensar as noções de integralidade por meio da afirmação de uma "(...) lógica interna com significações que lhe conferem sua clareza e sua inteligibilidade" (MENDONÇA, 1983, p. 19). A partir dessa questão é possível perceber como as noções de integralidade objetivaram-se, principalmente no sentido de refletir criticamente sobre elas e sobre as mudanças em seus possíveis significados.

\section{NOÇÕES DE INTEGRALIDADE, NECESSIDADES SOCIAIS EM SAÚDE E A FORMAÇÃO PROFISSIONAL}

Para que se possa compreender as noções de integralidade dentro da formação dos futuros profissionais da área de saúde, é necessário que os docentes tenham em mente o que se faz importante para a

\footnotetext{
$\overline{{ }^{6} \text { No portal PenseSus }}$ da Fundação Oswaldo Cruz, a ideia de reforma sanitária é definida como: "conjunto de ideias que se tinha em relação às mudanças e transformações necessárias na área da saúde. Essas mudanças não abarcavam apenas o sistema, mas todo o setor saúde, em busca da melhoria das condições de vida da população". Assim, médicos e outros profissionais da saúde pública passaram a trabalhar no sentido de ampliar os espaços dos debates políticos relacionados à saúde e a outras áreas do bem-estar da população.
} 
efetivação das mesmas, e que esse processo de ensino-aprendizagem dialogue com o projeto pedagógico dos cursos dentro da respectiva área (GONZÁLEZ; ALMEIDA, 2010).

Dentro da formação dos futuros profissionais da área de saúde, o princípio das noções de integralidade deve ser desenvolvido por meio de práticas voltadas para o diálogo entre professor e aluno, objetivando a melhor forma possível de discussão, intuindo levar este princípio para a prática do cotidiano (CAMARGO et al., 2015).

O processo do cuidado na formação deve ser pautado nas noções de integralidade, levando, assim, em consideração, o contexto do indivíduo, ações que promovam o autocuidado e o cuidado com o outro, as relações sociais que permeiam a vivência deste sujeito e, sobretudo, a sua autonomia com relação ao conhecimento para com a sua saúde.

Nesse contexto de formação profissional, as noções de integralidade buscam romper com a forma de ensino tradicional, voltada para a fixação de determinados conteúdos, e apontam para o ensino do pensamento crítico e reflexivo, analisando o contexto para que assim se possa tomar a melhor providência com relação ao problema do sujeito doente ou do indivíduo que busca os serviços de saúde (CAMARGO et al., 2015).

Aspectos tecnicistas comumente predominantes dentro da formação dos futuros profissionais da área de saúde, fazem com que estes saiam de seus cursos para o campo de atuação, condicionados a realizarem procedimentos sem, ao menos, verificarem o contexto em que estão inseridos. A análise desse contexto pode, em muitos casos, fazer a diferença entre somente diagnosticar o problema ou diagnosticar e tratar as possíveis causas do mesmo, para que, dessa forma, não seja recorrente.

Essa análise rompe com o processo que predomina no sistema de saúde brasileiro, cuja prática é reducionista, ou seja, o sujeito chega para atendimento, passa pela consulta para identificar a doença que, em sua maioria, já está instaurada, e recebe tratamento. Interessante que esse processo segue uma lógica cartesiana que sai do doente em direção ao que trata da sua doença, momento em que ela deixa de pertencer a ele, passando a pertencer ao médico, ou a quem, naquele momento, representa o status quo vigente (FOUCAULT, 2011).

Tal premissa renega a ideia de que o sujeito doente se constitui a partir de um todo que envolve suas singularidades enquanto pessoa e as condições do meio onde está contido, locus onde inserem-se as necessidades sociais. A partir do momento em que o discurso biomédico esquece da análise integral destas duas esferas, ele não permite ao sujeito a sua integralidade enquanto ser.

É justamente o contexto que permeia estes dois pontos cartesianos que se faz importante para o entendimento das noções de integralidade. Analisar os pontos que levaram o sujeito a procurar atendimento médico, estabelecer um diálogo entre equipe profissional e paciente, realizando perguntas para se conhecer melhor a vivência deste e também de seu contexto familiar, pode, em muitos casos, ajudar a solucionar o problema que o levou a procurar o serviço de saúde, curando não apenas a doença, mas também não deixando que a mesma retorne, em razão das influências externas referentes ao meio onde este sujeito está inserido.

As noções de integralidade e as necessidades sociais em saúde são construídas a partir de um processo de universalidade de acesso. Cecílio nos aponta um terceiro componente, a equidade, ${ }^{7}$ na qual

(...) a integralidade e a equidade, enquanto objetivos da atenção em saúde, vão além do simples "consumo" ou acesso a determinados serviços e nos remetem ao campo da(s) micropolítica(s) de saúde e suas articulações, fluxos e circuitos (CECílIO, 2009, p. 117).

A equidade e a integralidade nos levam a visualizar como estão sendo tratadas/geridas as políticas de saúde, ou, como definido por Cecílio, "o sistema de saúde" (CECÍlIO, 2009, p. 117). Isso “(...) implica, necessariamente, repensarmos aspectos importantes da organização do processo de trabalho, gestão, planejamento e construção de novos saberes e práticas em saúde" (CECÍlIO, 2009, p. 117).

Essa implicação em repensar os aspectos organizacionais do atual sistema de saúde e atendimento aos usuários, representa um desafio para os profissionais que nele estão inseridos, garantindo que os mesmos sejam capazes de se apropriar dos conceitos referentes às necessidades sociais em saúde no seu fazer diário. A partir daí estes profissionais tornar-se-iam capazes de compreender as pessoas na sua totalidade que procuram seus serviços, promovendo uma atenção à saúde mais humanizada (CECÍLIO, 2009).

\footnotetext{
No Dicionário da Educação Profissional em Saúde, disponível no portal da Fundação Oswaldo Cruz, a equidade é defina como "acesso universal e igualitário às ações e serviços” de saúde (ESCOREL, 2009).
} 
Em razão da dificuldade encerrada no processo de compreensão das necessidades sociais em saúde, percebemos a importância em consolidar no campo pedagógico um modo de orientar a formação profissional em saúde, traduzindo-se nas ações que permeiam todo o processo de ensino-aprendizagem e que se estenderão para os serviços de assistência (LIMA et al., 2013).

Construída por meio da reflexão coletiva sobre o contexto das práticas de ensino e de saúde, as noções de integralidade constituem-se em instrumento de ações que são alicerçados no diálogo entre acadêmicos, docentes, trabalhadores do serviço de saúde e usuários, que tem por finalidade promover, tratar e recuperar a saúde da população.

A partir desse processo de diálogo entre todas as esferas, dá-se conta de que o objeto deste discurso também pode tornar-se um sujeito do mesmo (FOUCAULT, 2011). Ou seja, de coadjuvante no contexto referente à saúde, o indivíduo pode tornar-se ator principal, alterando em profundidade as discussões em relação a este contexto. Desta forma, o percurso inerente às noções de integralidade garante ao sujeito um ato de tornar-se empoderado porque não mais partido em duas esferas, conforme preconizado anteriormente. ${ }^{8}$

As noções de integralidade evocam o fortalecimento da articulação entre as esferas ensino, gestão, assistência e controle social, como postulado por Ceccim e Feuerwerker (2004), a fim de se desconstruir modos de pensar já cristalizados na forma de produzir saúde.

Este processo aponta na direção de um modelo que finalize a perpetuação da formação profissional centrada no corpo e sistemas orgânicos, da prática assistencial especializada dependente de tecnologias e equipamentos para a realização de diagnósticos e tratamentos. Scliar (2007) solicita que de tal processo seja pensada "(...) uma proposta racionalizadora, mas [que] é também uma proposta política; em vez da tecnologia sofisticada oferecida por grandes corporações" (p. 39).

As noções de integralidade, tomadas como eixo norteador da formação em saúde, poderão contribuir para operacionalizar mudanças e indicar novos espaços e responsabilidades sociais para as instituições de ensino, que, por sua vez, compreenderão as deman-

\footnotetext{
${ }^{8}$ Neste artigo utilizamos o termo de poder na perspectiva de Horochovsk e Meirelles (2007), quando anuem que o processo de conferir poder ao indivíduo lhe dá uma maior autonomia.
}

das populacionais com maior proximidade e poderão formar profissionais aptos a responder por tais demandas efetivamente. Assim, serão desenvolvidas as condições de atendimento mais coerentes às necessidades de cada população.

Para completar este contexto de forma a torná-lo eficaz, é preciso refletir em uma mudança no que se refere ao processo de formação profissional, conforme preconizado supra. Dadas as questões já abordadas, entendemos que no seu ensino tradicional os futuros profissionais não são formados de forma a atender o escopo relativo às noções de integralidade. Por isso a necessidade de conciliar esforços entre as universidades e o sistema de saúde, onde surgem as necessidades da comunidade no sentido do financiamento da qualidade na formação dos profissionais de saúde (GONZE, 2009).

\section{CONSIDERAÇÕES FINAIS}

As noções de integralidade pressupõem problematizar a experiência clínica, dando-lhe um contexto mais complexo, porque oriundo de uma discussão coletiva por meio do contato de todos os atores vigentes no processo de problematização e formação da integralidade, os quais, neste mettier, devem ter uma voz equânime, pois todas estas vozes falam de uma situação comum, mas não necessariamente recíproca (FOUCAULT, 2011).

Desta forma, esta premissa constitui em um termo que permite identificar os sujeitos na condição de totalidades, considerando todas as dimensões possíveis de intervenção, de forma que o atendimento integral ultrapassa a estrutura organizacional hierarquizada e regionalizada da assistência em saúde. Este processo engloba a qualidade da atenção individual e coletiva aos usuários do sistema, percebidos como sujeitos históricos, sociais e políticos, articulados em sua conjuntura (MACHADO et al., 2007).

As noções de integralidade devem ser inseridas no processo de formação do profissional da saúde e somente serão efetivamente esclarecidas quando utilizadas na práxis cotidiana. É primordial, nesse contexto, a união das universidades e do SUS visando o aprimoramento da formação destes profissionais, para que tenham a perspectiva de oferecer assistência ao indivíduo e à comunidade de forma totalizante.

Esse contexto constitui-se em uma proposta de ação estratégica para transformar a organização dos processos formativos e dos serviços. Isso implica a recusa do reducionismo e a objetivação dos sujeitos com o intuito de viabilizar o diálogo, bem como 
implica compreender a saúde a partir de uma visão ampliada e totalizante. Isso requer articular saberes e práticas multi e interprofissionais para melhor responder às necessidades sociais da população (CECCIM; FEUERWERKER, 2004).

Tal condição exige que os cuidados primários em saúde sejam avaliados e analisados por intermédio da realidade e da conjuntura social de cada ambiente, prevendo modelos assistenciais que promovam a integração do setor de saúde aos demais setores, no intuito de criar políticas que sejam efetivas ao contexto e atendam às necessidades dos sujeitos participantes da sua realidade, avançando além das questões nosológicas que hoje norteiam a avaliação dos pacientes.

A noção de nosologia, tal como a conhecemos na atualidade, cria a cisão entre o sujeito doente e as necessidades sociais, pois não é capaz de relacioná-las, uma vez que os indivíduos formados, a partir desse modelo tecnicista, apenas compreendem o fato do diagnóstico a partir do sintoma não o inserindo no contexto e inviabilizando, assim, um olhar holístico sobre o sujeito doente.

Desse modo, as noções de integralidade inserem em seu corpus uma concepção de saúde-doença que, necessariamente, infere a formação de um profissional humanizado, expressando praticamente o que as referidas noções norteiam como práxis. Tal processo já é preconizado pelas Diretrizes Curriculares Nacionais (LIMA et al., 2013), como as do curso de Enfermagem, que preveem a formação de um profissional com espírito humanista. Tal premissa, no entanto, ainda não é completamente executada, denotando a vacância entre as questões inerentes à integralidade e às ações profissionais.

\section{REFERÊNCIAS}

BRASIL. Congresso Nacional. Constituição da República Federativa do Brasil. Promulgada em 5 out. 1988. Brasília, DF. Disponível em: https://www.planalto.gov.br/ccivil_03/constituicao/constituicao.htm. Acesso em: 20 dez. 2016.

CAMARGO, R. A. A. et al. A formação do conceito de integralidade em saúde à luz da abordagem histórico-cultural. Revista Eletrônica de Enfermagem, Goiânia, v. 17, n. 4, p. 1-10, 2015.

CECCIM, R. B.; FEUERWERKER, L. C. M. O Quadrilátero da formação para a área da saúde: ensino, gestão, atenção e controle social. Physis - Revista de Saúde Coletiva, Rio de Janeiro, v. 14, n. 1, p. 41-65, 2004.
CECÍLIO, L. C. O. As necessidades de saúde como conceito estruturante na luta pela integralidade e equidade na atenção em saúde. In: PINHEIRO, R.; MATTOS, R. A. (org.). Os sentidos da integralidade na atenção e no cuidado à saúde. Rio de Janeiro: Uerj; IMS; Abrasco, 2009. p. 117-130.

CORDEIRO, H. O instituto de medicina social e a luta pela reforma sanitária. Physis - Revista de Saúde Coletiva, Rio de Janeiro, v. 14, n. 2, p. 343-362, 2004.

ESCOREL, S. Equidade em saúde. 2009. Disponível em: http://www.sites.epsjv.fiocruz.br/dicionario/verbetes/equsau.html. Acesso em: 15 nov. 2016.

FOUCAULT, M. O nascimento da clínica. 7. ed. Rio de Janeiro: Forense Universitária, 2011.

GONZÁLEZ, A. D.; ALMEIDA, M. J. Integralidade da saúde: norteando mudanças na Graduação dos novos profissionais. Ciência e Saúde Coletiva, v. 15, n. 3, p. 757-62, 2010.

GONZE, G. G. A integralidade na formação dos profissionais de saúde: tecendo saberes e práticas. 2009. Dissertação (Mestrado em Saúde Coletiva) - Universidade Federal de Juiz de Fora, Juiz de Fora, 2009.

HOROCHOVSKI, R. R.; MEIRELLES, G. Problematizando o conceito de empoderamento. In: SEMINÁRIO NACIONAL MOVIMENTOS SOCIAIS, PARTICIPAÇÃO E DEMOCRACIA, 2., 2007, Florianópolis. Anais [...]. Florianópolis: UFSC; Núcleo de Pesquisa em Movimentos Sociais, 25 a 27 abr. 2007. p. 485-506.

LIMA, M. M. et al. Integralidade como princípio pedagógico na formação do enfermeiro. Texto e Contexto Enfermagem, Florianópolis, v. 22, n. 1, p. 106-113, 2013.

MACHADO, M. F. A. S. et al. Integralidade, formação de saúde, educação em saúde e as propostas do SUS - uma revisão conceitual. Ciência \& Saúde Coletiva, Rio de Janeiro, v. 12, n. 2, p. 333-342, 2007.

MATTOS, R. A. Os sentidos da integralidade: algumas reflexões acerca de valores que merecem ser definidos. In: PINHEIRO, R.; MATTOS, R. A. (org.). Os sentidos da integralidade na atenção e no cuidado à saúde. Rio de Janeiro: Uerj; IMS; Abrasco, 2009. p. 43-68.

MENDONÇA, N. D. O uso dos conceitos (uma tentativa de interdisciplinaridade). Bagé: FAT; Funba, 1983.

PAIM, J. et al. O sistema de saúde brasileiro: história, avanços e desafios. Veja, série 1/6 Saúde no Brasil, São Paulo, v. 67, n. 11, p. 1-11, 2011.

PENSE SUS. Disponível em: http://pensesus.fiocruz.br/reforma-sanitaria. Acesso em: 26 out. 2016.

PRADO JR., C. Formação do Brasil contemporâneo: colônia. São Paulo: Cia das Letras, 2011.

SCLIAR, M. História do conceito de saúde. Physis - Revista de Saúde Coletiva, Rio de Janeiro, v. 17, n. 1, p. 29-41, 2007. 